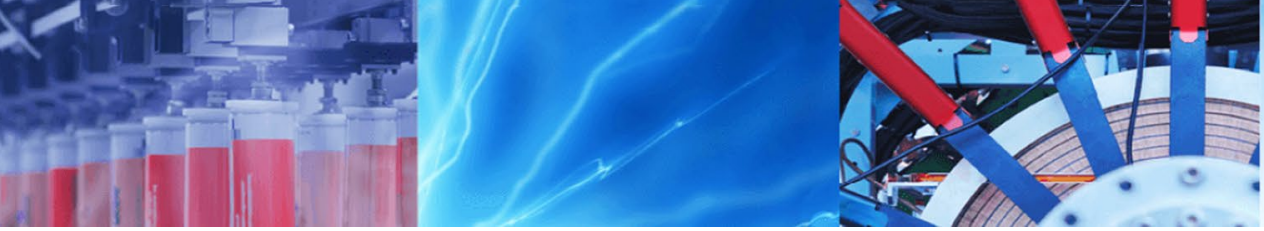

Research Article

\title{
Carbon capture using amine modified porous carbons derived from starch (Starbons ${ }^{\circ}$ )
}

\author{
I. Sreedhar ${ }^{1}(1) \cdot$ R. Aniruddha ${ }^{1} \cdot$ Shivani Malik ${ }^{1}$
}

(c) Springer Nature Switzerland AG 2019

\begin{abstract}
Adsorption based carbon capture to address the serious concern of global warming has been gaining worldwide attention of researchers due to its inherent advantages vis a vis other technical options like absorption, membrane and cryogenic separations, chemical looping combustion etc. Porous carbons from biomass wastes are under focus currently owing to its abundance, simple synthesis and regeneration and flexibility to achieve the desired pore structure and chemical modification. Carbon capture studies using porous carbons from starch have received little attention when compared to other biomass precursors. Hence in this work, facile synthesis of porous carbons from corn and potato starch has been employed. These were then screened w.r.t physico-chemical properties using different analytical tools like XRD, FTIR and BET surface area. Amine loading was done by wet impregnation method at different levels from 10 to $30 \%$ by wt to enhance their CC performance. Process standardization was done to maximize the CC capacity w.r.t critical process parameters like carbonation time, temperature, loading level, biomass precursor etc. A reasonably good CC of $3.4 \mathrm{mmol} / \mathrm{g}$ has been achieved at the optimal conditions. Cyclic stability and regenerability studies were also conducted to assess their stability and long term deployment potential. Amine loading was found to have a positive influence in achieving higher CC but at the cost of cyclic stability. From our studies, we could state that Starbons have a great potential to act as green sorbent in $\mathrm{CC}$ and the technology is in nascent stage, there is a huge window for innovation in synthesis, structure and chemical modification.
\end{abstract}

Keywords Starbons ${ }^{\circ} \cdot$ Carbon capture · Process standardization · Cyclic stability · Amine modification

\section{Introduction}

According to recent Inter-Governmental Panel on Climate Change (IPCC) report, the concentration of $\mathrm{CO}_{2}$ in the atmosphere has significantly increased from $280 \mathrm{ppm}$ during pre-industrial period to more than $400 \mathrm{ppm}$ now primarily due to continuing dependence on fossil fuels for power generation and other applications. This led to global warming and the associated undesirable climate changes. Carbon capture (CC) in pre- or post-combustion modes has been found to be a potential tool to address this alarming phenomenon. The various technical options of CC were adsorption, absorption, membrane separation, chemical looping combustion and cryogenic separations
[1]. Though absorption using solvents like amines was under focus for some time due its higher efficiency, it suffers from serious drawbacks like expensive process, energy intensive solvent regeneration, toxic emissions, equipment corrosion and solvent degradation and associated losses [2]. Recently, focus has been shifted to adsorption based carbon capture which is simple and environmentally friendly, economical process, higher energy efficiency, availability of variety of sorbents from even industrial and agricultural residues, wide temperature ranges of CC [3]. Various types of sorbents have been employed at different temperature ranges viz., low temperature sorbents (up to $200^{\circ} \mathrm{C}$ ) based on solid-amines, porous carbons, graphene or graphite, zeolites, MOFs, ILs, silica, polymer, clay etc.,

I. Sreedhar, isreedhar2001@yahoo.co.in | 'Department of Chemical Engineering, BITS Pilani Hyderabad Campus, Hyderabad, India.

SN Applied Sciences (2019) 1:463 | https://doi.org/10.1007/s42452-019-0482-8

Received: 25 January 2019 / Accepted: 11 April 2019 / Published online: 16 April 2019 
intermediate temperature sorbents $\left(200-400^{\circ} \mathrm{C}\right)$ based on $\mathrm{LDH}, \mathrm{MgO}$ etc. and high temperature sorbents $\left(>400^{\circ} \mathrm{C}\right)$ based on $\mathrm{CaO}$, alkali zirconates etc [4]. Among these sorbents, carbon based sorbents are gaining researchers' attention owing to their low cost of synthesis, light weight, large surface area and pore volume, moisture resistant, simple regeneration, low energy consumption, flexibility to pore structure modification and functionalization besides synthesis using cheap raw materials like biomass and industrial wastes. But they are found to be temperature sensitive and exhibit poor selectivity and capture capacity. These issues were found to be successfully addressed by proper control of pore structure during synthesis and by using amine functionalization through loading or grafting methods [5].

In recent past, among various sorbents mentioned above, porous carbons have been widely employed due to their low cost, high availability, thermal and mechanical stability, hydrophobicity, large surface area, easy to design pore structure and chemical resistance to acidic and basic conditions. For large scale applications, biomass sources have been identified as cost effective raw materials to synthesize these porous carbons even with functionalization [6]. Bio-wastes are available in abundance, cheap and naturally occurring with rich lingo-cellulosic compounds which could be converted to porous carbons by carbonization followed by activation through physical or chemical routes [7]. Studies have been reported on the use of activated carbons in CC applications generated through various biomass sources viz., ligno-cellulosic waste from palm agri-residue [8], coconut shell [9], Argan fruit shells [10], corn stover [11] etc.

In our present work, CC studies were conducted using porous carbons derived from starch of corn and potato with and without amine loading by wet impregnation method. These porous carbons, which were named as 'Starbons' as in starch based pororous carbons, were first synthesized by Budarin et al. [12] in league with York University in an attempt to produce new porous, solid adsorbents. The primary reason for the selection of the above mentioned Starbons in primarily due to the novelty of their usage in CC studies. At present, there are no published articles on the potential of these adsorbents in carbon dioxide capture. The ease of synthesis is also another factor that motivated to the selection of Starbons. As shall be explained later, the synthesis of these materials is relatively economic and fairly easy. Along with these factors, the potential of tunable surface area, pore volume and its capacity as a support was also of an industrial and academic interest. Another most important reason as to why Starbons ${ }^{\circ}$ were chosen was that they are clean to produce. The facile synthesis protocol, characterization studies to understand the physico-chemical attributes of the carbons, process standardization to maximize the CC capacity w.r.t key parameters like temperature, carbonation time, amine loading level and cyclic stability studies were conducted and the results obtained were compared with those reported.

\section{Experimental}

\subsection{Materials and methods}

The materials used for the synthesis of Starbons ${ }^{\bullet}$ were water, starch powder (Corn starch and Potato starch), ethanol and a small amount of an organic acid ( $p$-toluenesulphonic acid). Mono-ethanolamine was used for loading/ loading purposes.

Lab scale synthesis of Starbons as shown in Fig. 1 below involved three major steps viz., retro gradation, drying and carbonization and the protocol followed was similar to that reported by Shuttleworth et al. [13].

The respective starch powder was initially gelatinized by mixing it with water in a ratio of $1 \mathrm{~g}$ of starch to $20 \mathrm{~mL}$ of water. This is then heated to $70-80^{\circ} \mathrm{C}$ at a constant rate for $2 \mathrm{~h}$ with continuous stirring followed by refrigeration for nearly 2 days to form a solid gel. It was observed that while

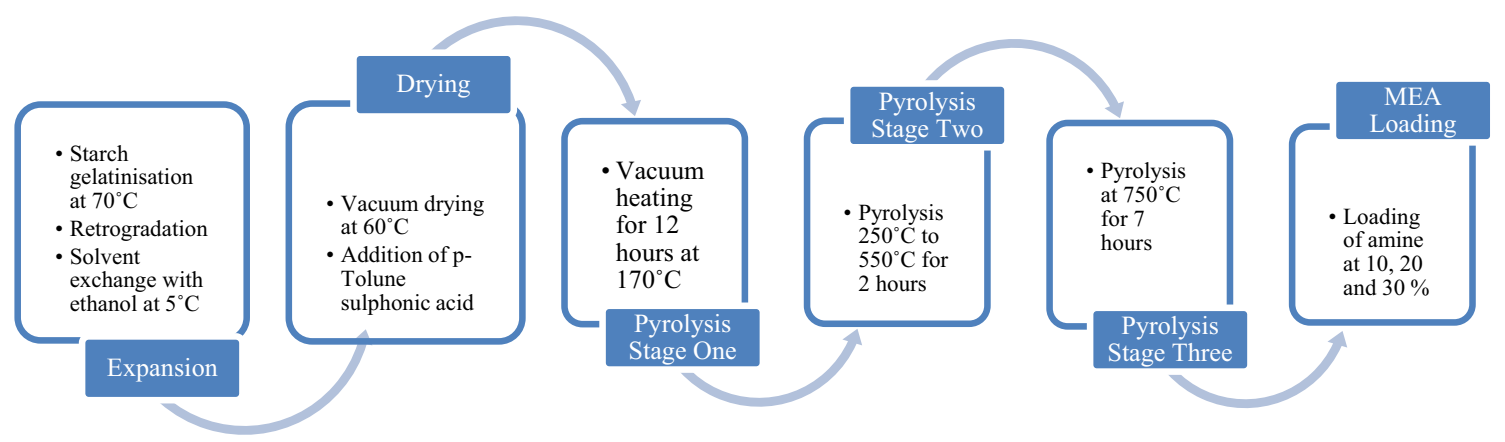

Fig. 1 Starbon synthesis flow chart 
potato starch has taken 1 day to form a gel, corn starch has taken nearly 2 days at almost similar temperatures of heating. Post-retrogradation, the gel block was then exchanged with ethanol of volume equal to that of water used in former step, stirred well and filtered to remove the excess solvent. The residue was then vacuum dried at $60^{\circ} \mathrm{C}$ for a day and then loaded with small amount of $p$-toluene sulphonic acid before pyrolysis. The pyrolysis was conducted within a range of temperatures $200^{\circ} \mathrm{C}$ to $800{ }^{\circ} \mathrm{C}$ and under vacuum [13]. Carbonization, the final stage, was carried out in two steps viz., heating the oven dried gel to $170^{\circ} \mathrm{C}$ in vacuum for about half a day followed again by pyrolysis at various temperatures between 200 and $800^{\circ} \mathrm{C}$ for 3-4 $\mathrm{h}$ in an inert environment of $\mathrm{N}_{2}$. The Starbons thus synthesized were given nomenclature based on the biomass source and carbonization temperature like PS-250 implies starbon from potato starch carbonized at $250^{\circ} \mathrm{C}$. These Starbons ${ }^{\circ}$ were then impregnated with MEA (MonoEthanolamine) at various loading levels of $10 \%, 20 \%$ and $30 \%$ (wt) by wet impregnation method. Wet impregnation involved the addition of the porous to the required predetermined weight percent of amine in a water/ethanol solution, after which the mixture is heated to $105^{\circ} \mathrm{C}$ to remove the water/ethanol content [14].

\subsection{Characterization tools}

The analytical tools employed to understand the physicochemical changes in these studies were D5000 SIEMENS $\mathrm{X}$-ray diffractometer using $\mathrm{Ni}$-filtered CuKa radiation $(\lambda=1.506 \AA)$ for assessing crystalline nature, SEM Carl Zeiss AG-EVO, 40 Series at an accumulation voltage of $10 \mathrm{kV}$ and system resolution of $98 \mathrm{eV}$ for morphological studies and BET Surface analyzer from Smart instruments for surface area and pore volume measurements. FTIR studies were done using spectrophotometer of Thermo Fisher Scientific make.

\subsection{Experimental set-up and procedure for carbon capture studies}

The experimental set-up employed for our studies consists of a fixed bed reactor with necessary temperature controls and an integrated pre-heater. The reactor was made of quartz that could withstand temperatures up to $1200^{\circ} \mathrm{C}$. Figures 2 and 3 below show the line diagram and photograph of the experimental set-up respectively. The pre-heater could be used to achieve high temperature of gas mixture before entering into furnace (nearly $250^{\circ} \mathrm{C}$ ). The length and diameter of the quartz tube were $55 \mathrm{~cm}$ and $2.54 \mathrm{~cm}$ respectively. Gas leakage was prevented using an inert graphite gasket ring installed in the reactor. Thermocouples were installed at various locations of the reactor to record the temperatures as a function of time and position during the $\mathrm{CC}$ studies.

The desired amount of adsorbent was loaded into the quartz tube and was fixed into the experimental set-up to function as a fixed bed reactor. The power was switched ON and the inert $\mathrm{N}_{2}$ gas was purged at atmospheric pressure. Heating was continued till the desired temperatures were attained. The $\mathrm{CO}_{2}$ and $\mathrm{N}_{2}$ gases were made to flow through the reactor at a pre-determined composition. The flow rates of these gases were regulated by the mass flow controller to attain the desired composition. The exit gas composition was measured by an online gas analyzer with data logging facility. The CC data as a function of time was recorded to plot the required breakthrough curves [15]. The CC achieved was estimated using the Eq. (1) below

$Q_{a d s}=\frac{F_{o}\left(\rho / M_{w t}\right)\left(C_{o}-C_{a}\right) T_{q}}{W}$
Fig. 2 The schematic diagram of the packed bed reactor

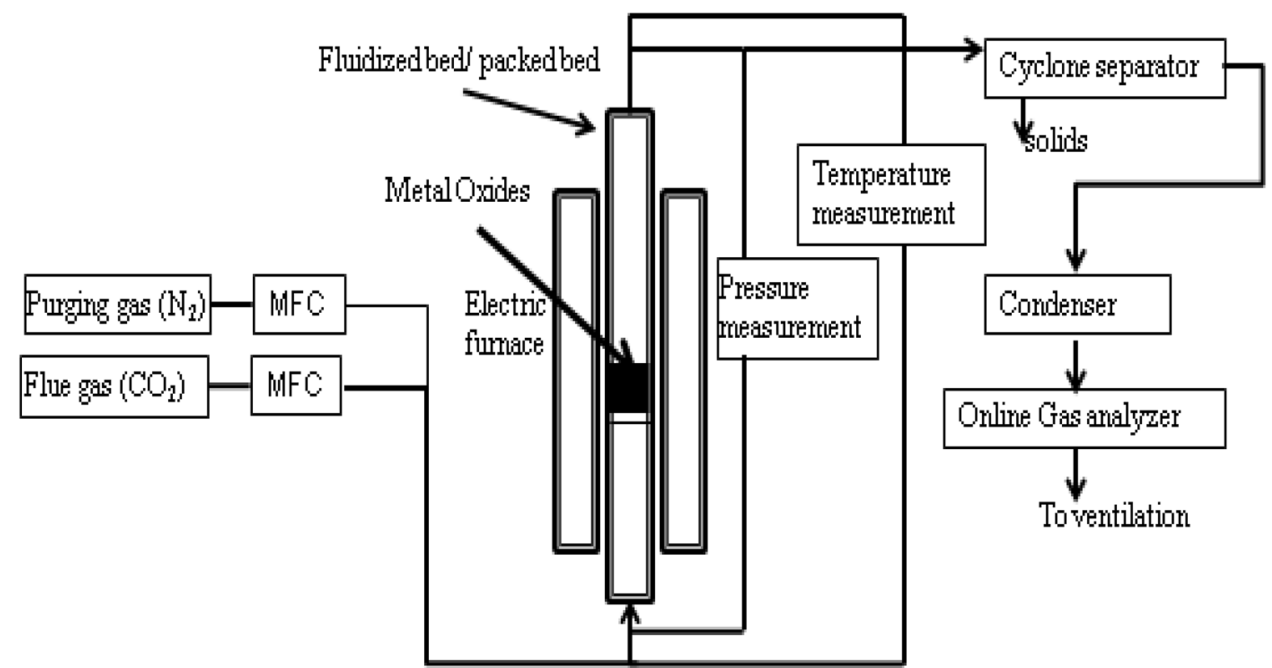

SN Applied Sciences A SPRINGER NATURE journal 
Fig. 3 Experimental packed bed reactor and its accessories

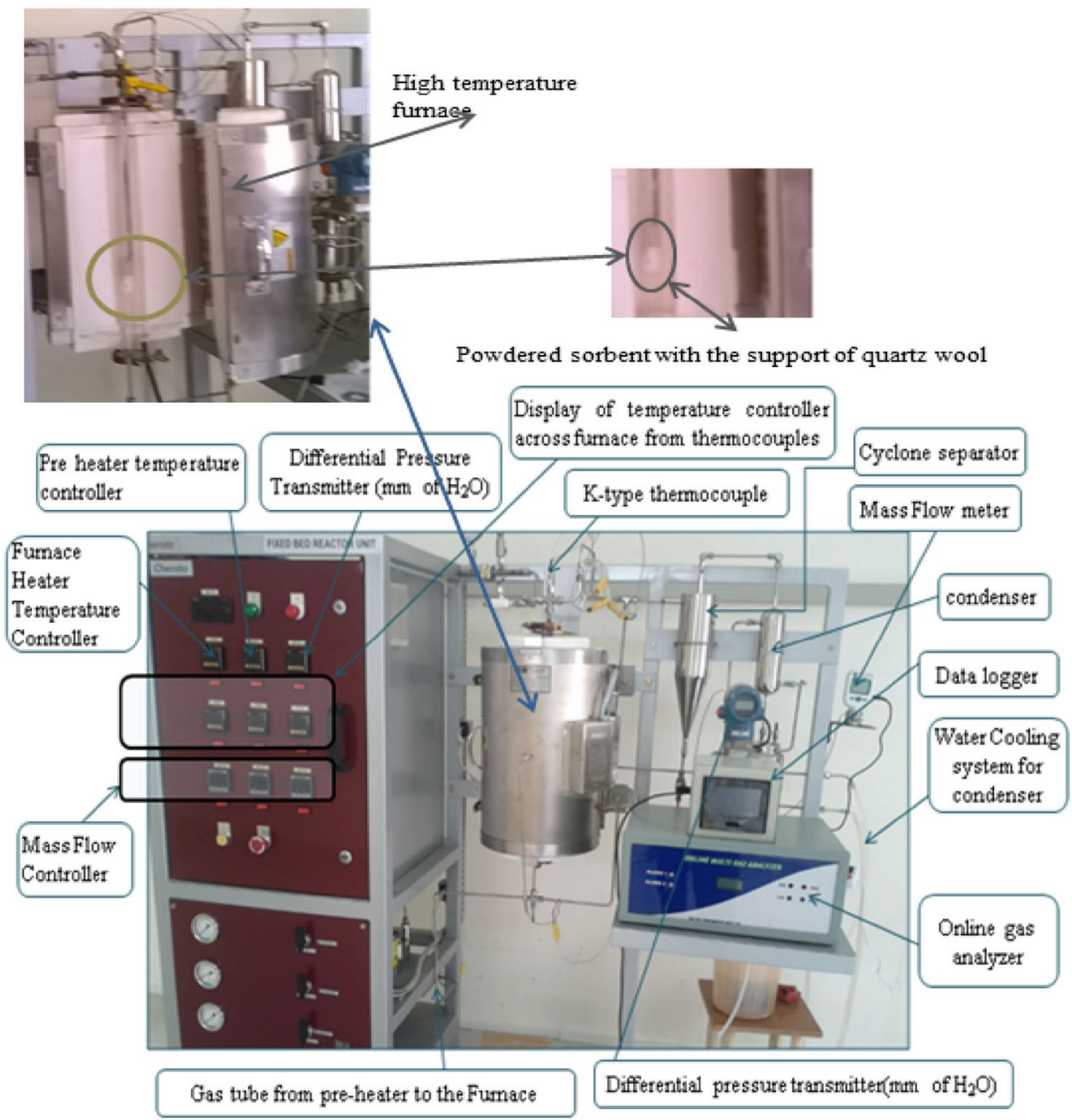

where $F_{\mathrm{o}}$ is feed flow rate $\left(\mathrm{cm}^{3} /\right.$ minute), $\rho$ is the density of $\mathrm{CO}_{2}$ gas at room temperature $\left(\mathrm{mg}\right.$ of $\left.\mathrm{CO}_{2} / \mathrm{cm}^{3}\right), M_{w t}$ is the molecular weight of $\mathrm{CO}_{2}$ gas, $\mathrm{Q}_{\mathrm{ads}}$ is $\mathrm{CO}_{2}$ capture capacity of adsorbent ( $\mathrm{mmol}$ of $\mathrm{CO}_{2} / \mathrm{g}_{\text {ads }}$ ), $\mathrm{W}$ is sorbent weight (grams), $\mathrm{T}_{\mathrm{q}}$ is breakthrough time taken to capture $\mathrm{CO}_{2}$ by the adsorbent (minutes) which is given by Eq. (2),

$T_{q}=\int_{t=0.05 C_{o}}^{t=0.95 C_{0}}\left(1-\frac{C_{a}}{C_{o}}\right) d t$

$\mathrm{C}_{\mathrm{o}}$ and $\mathrm{C}_{\mathrm{a}}$ are feed and outlet concentrations $\left(\mathrm{cm}^{3}\right.$ of $\left.\mathrm{CO}_{2} / \mathrm{l}\right)$ at time $t_{q}$ (minutes) respectively. In this case we have taken the $T_{q}$ as $60 \mathrm{~min}$ for further analysis of sorbent.

\section{Results and discussion}

\subsection{Physico-chemical characterization}

Starbons ${ }^{\circ}$ were initially prepared at four temperatures of $250^{\circ} \mathrm{C}, 350^{\circ} \mathrm{C}, 450^{\circ} \mathrm{C}, 550^{\circ} \mathrm{C}$ and as their BET surface areas were not found to be satisfactory, higher carbonization temperatures $\left(750^{\circ} \mathrm{C}\right)$ for longer durations $(6 \mathrm{~h})$ were employed and this could bring significant increase in surface area and pore volumes by successful removal of volatile components. Both starches i.e. potato and corn almost gave identical values. Owing to relatively simpler synthesis protocol, potato starch has been used for all further studies on CC.

BET surface area measurement was used to screen the synthesis protocols of Starbons from both the types of starch. Table 1 below gives the summary of these results which clearly showed that increase in carbonization temperature along with the duration of pyrolysis resulted in significant increase in the surface area and pore volume due to effective removal of volatile components present in the Starbons.

From the FTIR results shown in Fig. 4, it was evident that CS 750 and PS-750 Starbons were almost identical and matched with that of commercially available activated carbon (AC) $[16,17]$.

\section{SN Applied Sciences}


Table 1 BET surface areas of Starbons ${ }^{\circ}$

\begin{tabular}{llll}
\hline Starbon & $\begin{array}{l}\text { Pyrolysis tem- } \\
\text { perature }\left({ }^{\circ} \mathrm{C}\right)\end{array}$ & $\begin{array}{l}\text { BET surface } \\
\text { area }\left(\mathrm{m}^{2} / \mathrm{g}\right)\end{array}$ & References \\
\hline CS 250 & 250 & $>1$ & In this study \\
CS 350 & 350 & 2.11 & In this study \\
CS 450 & 450 & 5.03 & In this study \\
CS 550 & 550 & 13.12 & In this study \\
CS 750 & 750 & 245.07 & In this study \\
PS 250 & 250 & $>1$ & In this study \\
PS 350 & 350 & 1.44 & In this study \\
PS 450 & 450 & 3.47 & In this study \\
PS 550 & 550 & 6.43 & In this study \\
PS 750 & 750 & 230.55 & In this study \\
Starbon @ $100^{\circ} \mathrm{C}$ & 100 & 179 & Ref [12] \\
Starbon @ $150^{\circ} \mathrm{C}$ & 150 & 172 & Ref [12] \\
Starbon @ 220 ${ }^{\circ} \mathrm{C}$ & 220 & 151 & Ref [12] \\
Starbon @ 300 ${ }^{\circ} \mathrm{C}$ & 300 & 293 & Ref [12] \\
Starbon @ $350^{\circ} \mathrm{C}$ & 350 & 332 & Ref [12] \\
Starbon @ $450^{\circ} \mathrm{C}$ & 450 & 475 & Ref [12] \\
Starbon @ $600^{\circ} \mathrm{C}$ & 600 & 528 & Ref [12] \\
Starbon @ $700^{\circ} \mathrm{C}$ & 700 & 538 & Ref [12] \\
Starbon @ $800^{\circ} \mathrm{C}$ & 800 & 600 & Ref [12] \\
\hline
\end{tabular}

To confirm the presence of amines in the loaded Starbons ${ }^{\circ}$, FTIR studies were conducted for three different samples of $10 \%, 20 \%$ and $30 \%$ MEA loaded Starbons. FTIR results shown in Figs. 5, 6 and 7 below confirmed the presence of amines $\left(\mathrm{NH}_{2}\right)$ from the peaks in the regions of $3400-3500 / \mathrm{cm}$ and $1650-1550 / \mathrm{cm}$.

XRD analysis was done on the two types of Starbons and the results shown in Fig. 8 below clearly indicates that they are identical and amorphous in nature. The plots also were similar to that of a commercial activated carbon [18-20].

\subsection{Carbon capture studies}

\subsubsection{Effect of loading}

Starbons ${ }^{\circ}$ were impregnated with MEA for the study of its effect on CC, with the loading percentages fixed at $10 \%, 20 \%$ and $30 \%$ initially. However, the final loading percentages were found (using gravimetric method) out to be $6.3 \%$ (for a $10 \%$ initial loading), $18.7 \%$ (for a $20 \%$ initial loading) and $27.4 \%$ (for a $30 \%$ initial loading). The effect of loading on CC was shown in Fig. 9 below. The highest CC value was exhibited by $30 \%$ loaded Starbon $(2.085 \mathrm{mmol} / \mathrm{g})$. From the results it was interesting to note that there was a critical or threshold loading amount beyond which only there was a positive influence of it on CC. The CC given $10 \%$ loaded starbon was found to be less than that of unloaded one. The reason for this might be that the amount of MEA available with respect to the blocked sites, decreased considerably in $10 \%$ MEA loaded starbon while MEA amount present in 20\% and 30\% MEA loaded Starbons ${ }^{\circledR}$ contributed to high CC values of the
Fig. 4 FTIR of corn and potato starch gel derived Starbons ${ }^{\circ}$ at $750^{\circ} \mathrm{C}$

Fig. 5 FTIR of $10 \%$ loaded Starbon
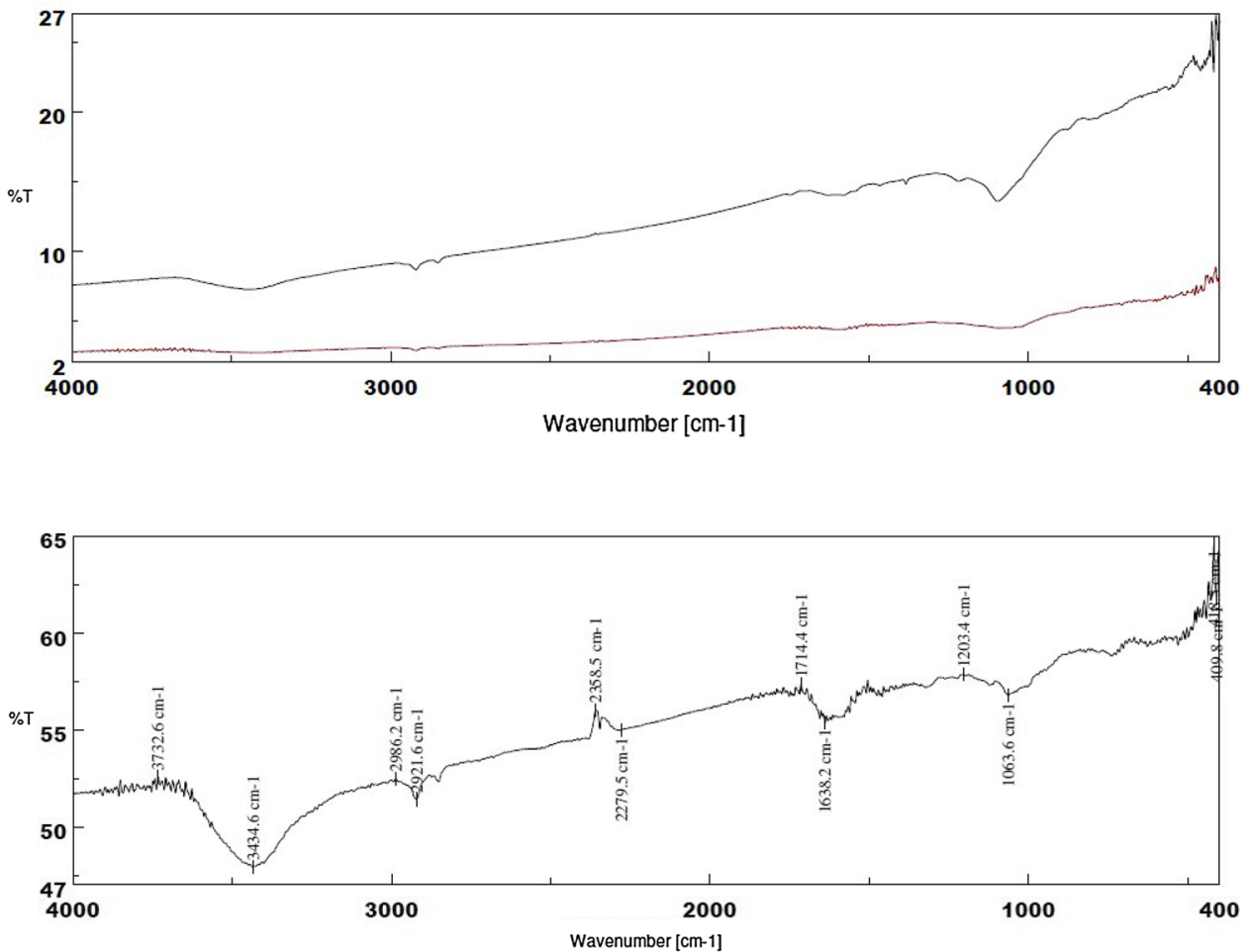

SN Applied Sciences 
Fig. 6 FTIR of $20 \%$ loaded Starbon

Fig. 7 FTIR of $30 \%$ loaded Starbon

Fig. 8 XRD of CS and PS Starbons

mentioned Starbons ${ }^{\circ}$. Cogswell et al. [21] has reported similar decreasing trends in CC value with increase in initial loading percentages in their study of $\mathrm{CO}_{2}$ capture using titanium pillared pure MCM-36 using the amine TEPA and imine PEI. For both, a decrease in CC values was observed. The TEPA loaded support in particular showed a decline
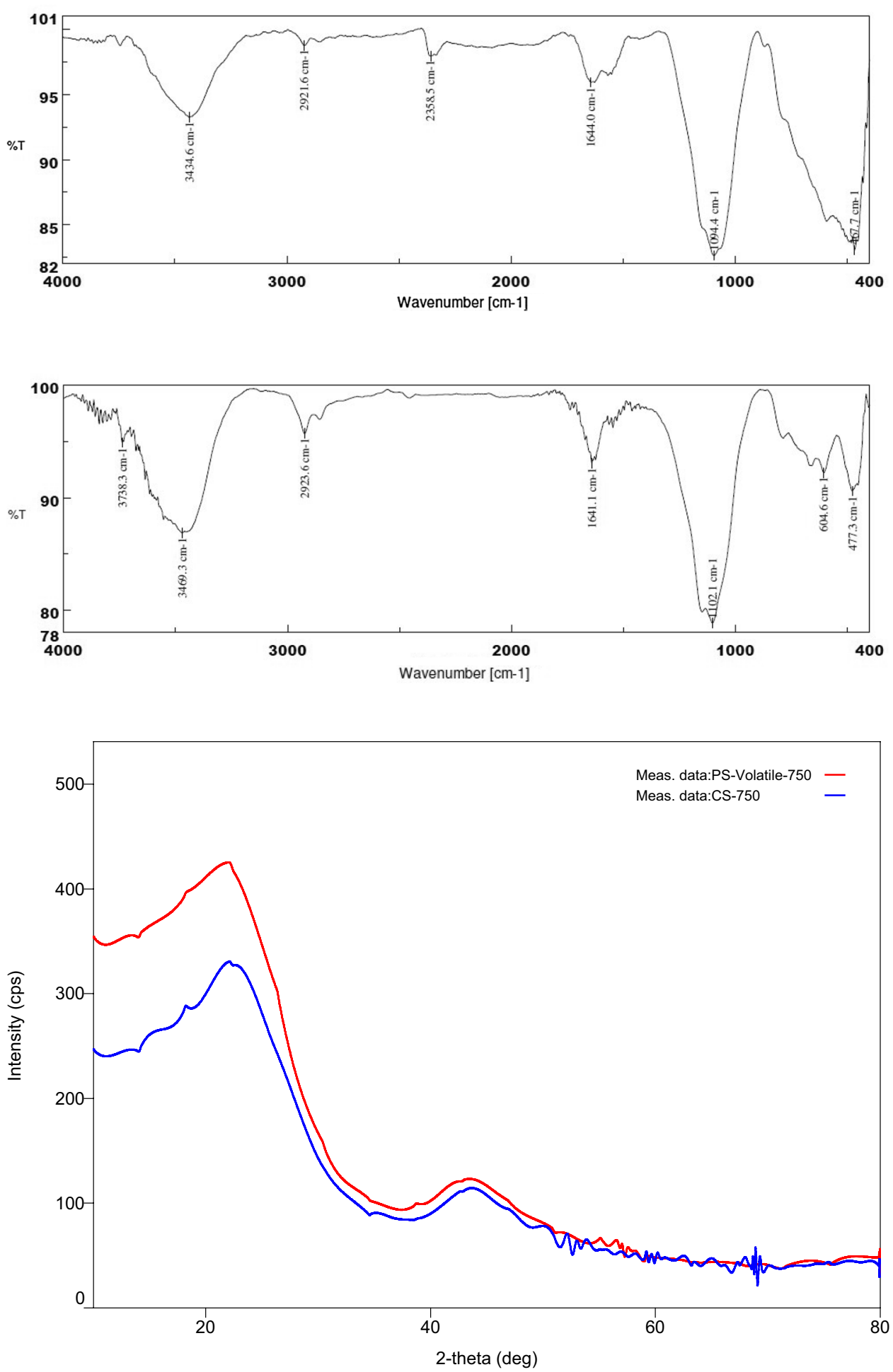

in CC values $(1.3 \mathrm{mmol} / \mathrm{g}$ at $5 \%$ wt loading to $0.2 \mathrm{mmol} / \mathrm{g}$ at $20 \% \mathrm{wt}$ loading and from thence to $0.5 \mathrm{mmol} / \mathrm{g}$ at $30 \%$ wt loading and finally at $1.75 \mathrm{mmol} / \mathrm{g}$ at $48 \% \mathrm{wt}$ loading) and the cause was attributed to a combination of low surface area (post the loading of amine) and the low content of amine itself. Returning to the present study, 
Fig. 9 Effect of loading on $\mathrm{CO}_{2}$ adsorption

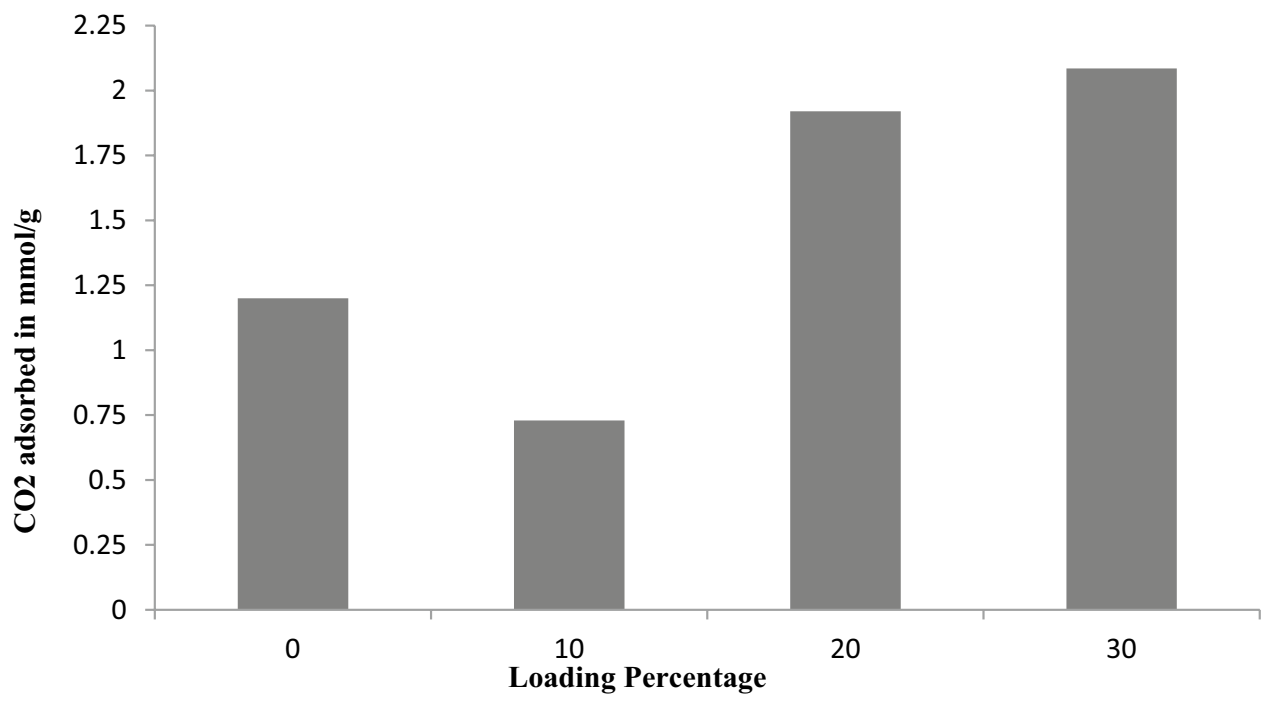

there was a significant increase in CC from $10 \%$ to $20 \%$ beyond which it was only marginal. Regarding the positive influence of loading on CC, Liu et al. [22] also observed in their studies, in which the adsorbents were porous phenolic resins loaded with polyethylene-amine giving CC values of $0.9 \mathrm{mmol} / \mathrm{g}, 1.75 \mathrm{mmol} / \mathrm{g}, 2.25 \mathrm{mmol} / \mathrm{g}$, $3.85 \mathrm{mmol} / \mathrm{g}$ for loading percentages 10\%, 20\%, 30\%, $40 \%$ respectively. Son et al. [23] also found in their study of PEI loaded mesoporous silica KIT-6 for loading percentages of $10 \%(0.341 \mathrm{mmol} / \mathrm{g}), 30 \%(1.455 \mathrm{mmol} / \mathrm{g})$, and $50 \%$ (3.068 mmol/g). Li et al's [24] conducted CC studies using $\mathrm{KOH}$-activated Biochar, and found that $\mathrm{CO} 2$ uptake increased with the weight of $\mathrm{KOH}$ present in the biochar $2 \mathrm{~g}, 2.5 \mathrm{~g}$ and $3.0 \mathrm{~g}$ of $\mathrm{KOH}$ per $0.5 \mathrm{~g} \mathrm{B-PC}$ for which the capture values were $23 \mathrm{mmol} / \mathrm{g}, 25 \mathrm{mmol} / \mathrm{g}$ and $26 \mathrm{mmol} / \mathrm{g}$ respectively. Gholidust et al. [25] further confirms that this was also the case with other amines like DEA $(0.4 \mathrm{mmol} / \mathrm{g}$,
$0.475 \mathrm{mmol} / \mathrm{g}, 0.525 \mathrm{mmol} / \mathrm{g}, 0.9 \mathrm{mmol} / \mathrm{g}$ for a set of loading values $0.22,0.52,0.62$ and $1.15 \mathrm{mmol}$ of $\mathrm{DEA} / \mathrm{g}$ of adsorbent at $\left.50{ }^{\circ} \mathrm{C}\right)$ and TEPA $(0.15 \mathrm{mmol} / \mathrm{g}, 0.22 \mathrm{mmol} / \mathrm{g}$, $0.5 \mathrm{mmol} / \mathrm{g}$ for a set of loading values $0.52,0.89$ and $1.03 \mathrm{mmol}$ of TEPA $/ \mathrm{g}$ of adsorbent at $50^{\circ} \mathrm{C}$ ) in which both the mentioned amines showed an increase in $C C$ values with the increase in loading amount of amines.

\subsubsection{Effect of temperature}

To understand the influence of temperature on capture capacity using the PS Starbons ${ }^{\circ}$ unloaded and loaded with MEA at various levels, CC studies were conducted at four temperatures of $25^{\circ} \mathrm{C}, 50{ }^{\circ} \mathrm{C}, 75^{\circ} \mathrm{C}$ and $100{ }^{\circ} \mathrm{C}$. From the results were shown in Fig. 10, it was clearly evident with increase in loading levels besides increase in overall capture capacity, there was a pronounced decrease in CC
Fig. 10 Effect of temperature on $\mathrm{CO}_{2}$ adsorption

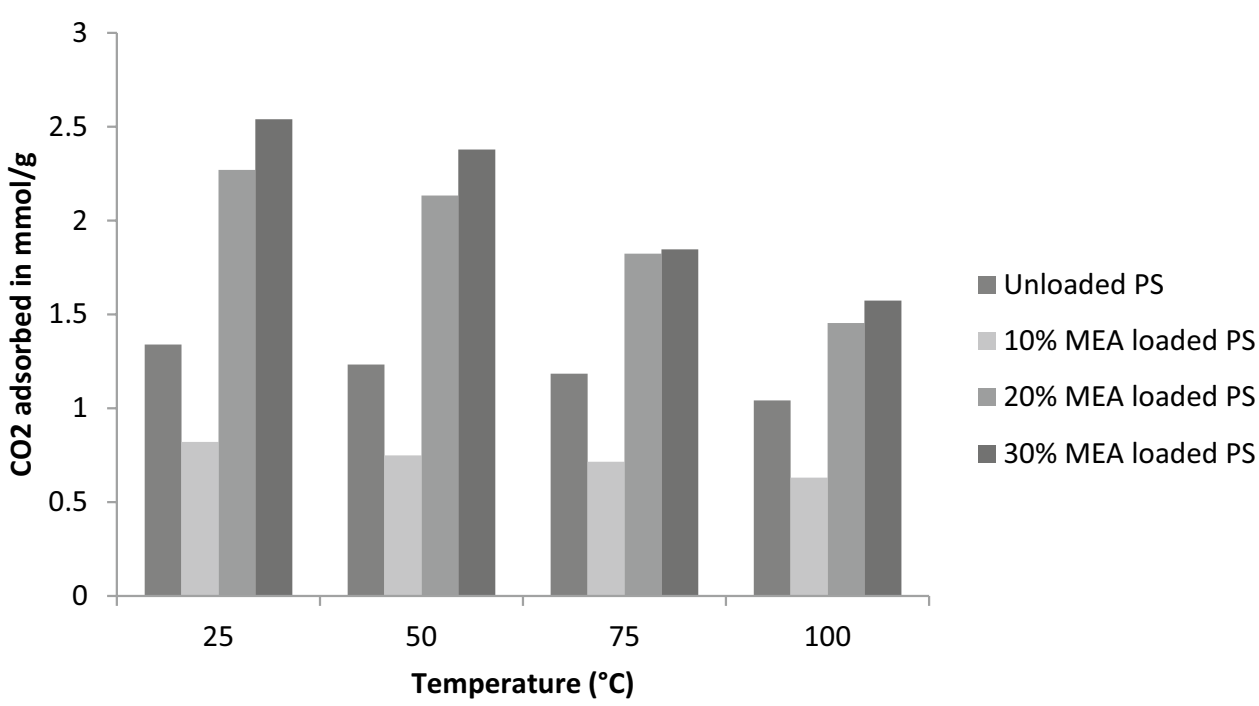

SN Applied Sciences a SPRINGER NATURE journa 
with increase in temperature. This effect of temperature on CC was marginal at low loading. Fiuza-Jr et al. [26] also reported similar trend in their $\mathrm{KOH}$ modified $\mathrm{AC}$ derived from yellow mombins, in which the $\mathrm{CO} 2$ capture was carried out at temperature from 0 to $75^{\circ} \mathrm{C}(3.2 \mathrm{mmol} / \mathrm{g}$, $1.6 \mathrm{mmol} / \mathrm{g}$ and $0.8 \mathrm{mmol} / \mathrm{g}$ over temperature ranges (0-25), (25-50) and (50-75) ${ }^{\circ} \mathrm{C}$ respectively). As mentioned before, 20 wt $\%$ and 30 wt $\%$ MEA loaded Starbons ${ }^{\circ}$ demonstrated relatively higher values of CC viz., $2.274 \mathrm{mmol} / \mathrm{g}$ and $2.54 \mathrm{mmol} / \mathrm{g}$ at $50{ }^{\circ} \mathrm{C}$ which clearly showed the positive effect of amine loading on capture capacity. Gholidoust et al. [25] reported similar trends with AC loaded with different amines such as DEA $(0.85 \mathrm{mmol} / \mathrm{g}$, $0.95 \mathrm{mmol} / \mathrm{g}$ at $25^{\circ} \mathrm{C} \& 50^{\circ} \mathrm{C}$ for a loading of $1.15 \mathrm{mmol}$ of DEA $/ \mathrm{g}$ of $A C), M D E A(0.16 \mathrm{mmol} / \mathrm{g}, 0.21 \mathrm{mmol} / \mathrm{g}$ at $25^{\circ} \mathrm{C} \& 50^{\circ} \mathrm{C}$ for a loading of $0.15 \mathrm{mmol}$ of MDEA/g of $\mathrm{AC}$ ) and TEPA $\left(0.4 \mathrm{mmol} / \mathrm{g}, 0.45 \mathrm{mmol} / \mathrm{g}\right.$ at $25^{\circ} \mathrm{C} \& 50^{\circ} \mathrm{C}$ for a loading of $1.77 \mathrm{mmol}$ of TEPA $/ \mathrm{g}$ of AC). The increase in CC values with $20 \%$ and $30 \%$ loaded Starbons ${ }^{\circ}$ from $25^{\circ} \mathrm{C}$ to $50{ }^{\circ} \mathrm{C}$ was due to higher reactivity of MEA towards $\mathrm{CO} 2$ at $50^{\circ} \mathrm{C}$ than at $25^{\circ} \mathrm{C}$. The decrease in CC values for both PS-750 and $10 \%$ loaded was due to the physical nature of adsorption.

\subsection{Cyclic studies}

The cyclic studies of all Starbons ${ }^{\circ}$ were carried out up to three cycles in which the regeneration or desorption temperature was fixed at $125^{\circ} \mathrm{C}$ for the loaded Starbons and $350^{\circ} \mathrm{C}$ for the unloaded. Table 2 shows the results of these studies which clearly show that starbon PS-750 was relatively more stable than others. Carbon capture values were found to decrease with each subsequent cycle for most of the Starbons though the extent of deterioration was different for each. The unloaded and $10 \%$ loaded Starbons were found to exhibit better cyclic stability vis-à-vis others like $20 \%$ and $30 \%$ loaded Starbons. The significant decrease in CC of loaded Starbons ( $20 \%$ and $30 \%$ ) could be attributed to the inherent volatility of MEA and hence its loss during every regeneration cycle besides its degradation which increased with loading level. PS-750 Starbons ${ }^{\circ}$ showed a gradual decay in CC probably due pore volume blockage after repeated cycles. Li et al's [27] work on the cyclic studies of CC using TEPA modified IM15 also gave similar trends viz., $2.5 \mathrm{mmol} / \mathrm{g}, 2.35 \mathrm{mmol} / \mathrm{g}$ and $2.25 \mathrm{mmol} / \mathrm{g}$ after first, second and third cycle respectively. The reason was found to be Amine leaching which was also explained in Ma et al's [28] cyclic adsorption-desorption of 50-TEPA/C8-Titanium oxide under $10 \%$ CO2/N2 at $75{ }^{\circ} \mathrm{C}$, where the $\mathrm{CC}$ values after each of the first three cycles were $1.75 \mathrm{mmol} / \mathrm{g}, 1.63 \mathrm{mmol} / \mathrm{g}$
Table 2 Cyclic performance of Starbons

\begin{tabular}{|c|c|c|c|c|}
\hline \multirow[t]{2}{*}{ Type of Starbon } & \multirow{2}{*}{$\begin{array}{l}\text { Tempera- } \\
\text { ture }\left(\text { in }{ }^{\circ} \mathrm{C}\right)\end{array}$} & \multicolumn{3}{|c|}{ CC value (in mmol/g) } \\
\hline & & Cycle 1 & Cycle 2 & Cycle 3 \\
\hline & 25 & 1.5 & 1.3 & 1.2 \\
\hline \multirow[t]{4}{*}{ PS-750 } & 50 & 1.4 & 1.2 & 1.1 \\
\hline & 75 & 1.3 & 1.2 & 1.1 \\
\hline & 100 & 1.1 & 1.0 & 0.9 \\
\hline & 25 & 0.9 & 0.8 & 0.7 \\
\hline \multirow[t]{4}{*}{$10 \%$ MEA loaded } & 50 & 0.8 & 0.7 & 0.6 \\
\hline & 75 & 0.8 & 0.7 & 0.6 \\
\hline & 100 & 0.7 & 0.6 & 0.5 \\
\hline & 25 & 2.7 & 2.3 & 1.6 \\
\hline \multirow[t]{4}{*}{$20 \%$ MEA loaded } & 50 & 2.9 & 2.2 & 1.5 \\
\hline & 75 & 2.3 & 1.7 & 1.3 \\
\hline & 100 & 1.8 & 1.4 & 1.1 \\
\hline & 25 & 3.0 & 2.3 & 1.8 \\
\hline \multirow[t]{3}{*}{$30 \%$ MEA loaded } & 50 & 3.2 & 2.4 & 2.0 \\
\hline & 75 & 2.3 & 1.9 & 1.4 \\
\hline & 100 & 2.0 & 1.6 & 1.1 \\
\hline
\end{tabular}

Table 3 Recovery of referenced porous adsorbents after three cycles

\begin{tabular}{lll}
\hline Porous adsorbent & $\begin{array}{l}\text { Recovery \% at the } \\
\text { end of } 3 \text { cycles }\end{array}$ & References \\
\hline PS-750 Starbon & 82 & In this study \\
10\% MEA loaded Starbon & 75 & In this study \\
20\% MEA loaded Starbon & 55 & In this study \\
30\% MEA loaded Starbon & 61 & In this study \\
TEPA-IM15 & 90 & Ref [24] \\
50-TEPA/C8-titanium oxide & 89 & Ref [27] \\
AC bead & 90 & Ref [28] \\
C8-Ti-30 & 70 & Ref [29] \\
\hline
\end{tabular}

and $1.56 \mathrm{mmol} / \mathrm{g}$. In Nguyen and Lee's [29] comparative study on $\mathrm{CO} 2$ adsorption of $\mathrm{AMBC}$ and $\mathrm{AC}$ beads, the latter was also reported to show only gradual reduction in adsorption values after subsequent cycles $(8.84 \mathrm{mmol} / \mathrm{g}$, $8.398 \mathrm{mmol} / \mathrm{g}$ and $7.956 \mathrm{mmol} / \mathrm{g}$ ). One more study on CC using C8-Ti-30 revealed a higher cyclic degradation i.e. $2.3 \mathrm{mmol} / \mathrm{g}, 1.61 \mathrm{mmol} / \mathrm{g}$ and $1.6 \mathrm{mmol} / \mathrm{g}$ at the end of the first three cycles. The Table 2 given below shows the cyclic performance of all Starbons (loaded and unloaded) at four different temperatures from which it is evident that cyclic stability decreased with increase in extent of loading and there exists an optimum temperature $\left(50^{\circ} \mathrm{C}\right.$ for most) at which CC was highest. Table 3 compares the percentage recovery of different Starbons $s^{\circ}$ vis-a-vis reported sorbents which showed that Starbons ${ }^{\circ}$ recovery was relatively less. 
Fig. 11 Effect of time on $\mathrm{CO}_{2}$ adsorption

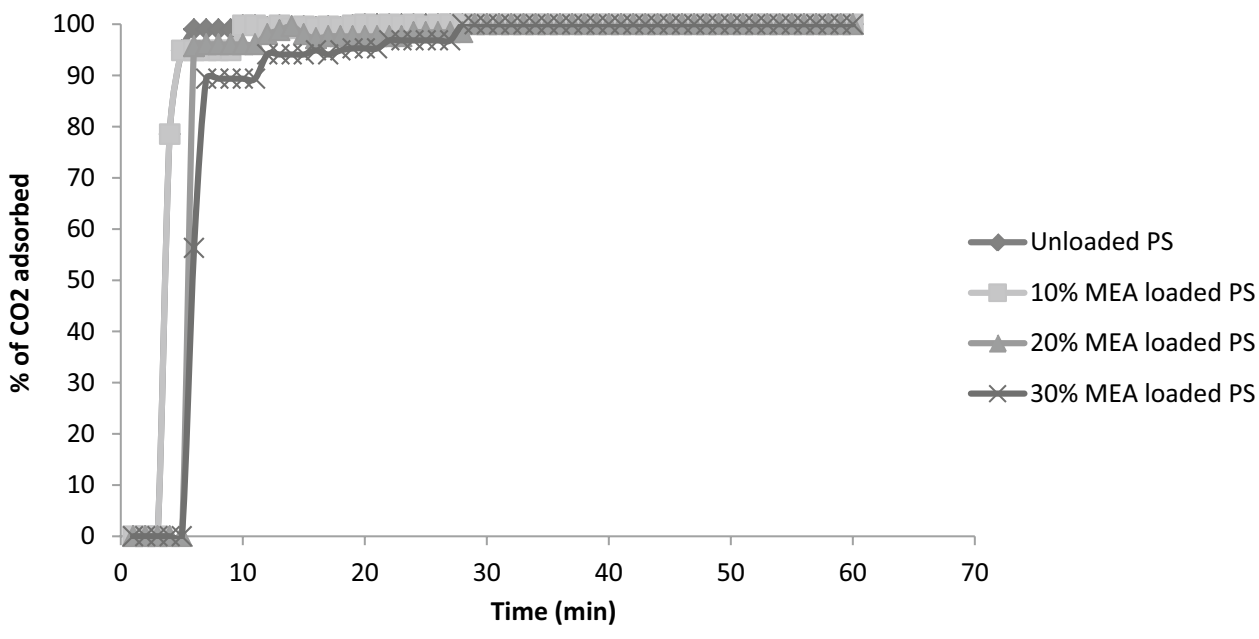

\subsection{Comparison of Starbons with reported sorbents}

\subsubsection{Breakthrough behavior}

Both carbonation and decarbonation (adsorption and desorption) processes were carried out for $60 \mathrm{~min}$ in total. The inference that could be drawn from Fig. 11 graph was that almost $100 \%$ saturation was achieved in very short time with PS-750 and 10\% MEA loaded Starbons even in less time than 10 min while $20 \%$ and $30 \%$ loaded Starbons ${ }^{\circ}$ took 20 min probably due to higher amine content and slower pore blockage with increased loading. Hence, the adsorption was found to be highly spontaneous, although only kinetic studies could reveal its intrinsic nature. Goel et al's [30] experiments using four different porous carbons (C-500, C-600, C-700 and C-800) enriched with nitrogen with a feed ratio of $1: 9\left(\mathrm{CO}_{2}: \mathrm{N}_{2}\right)$ at $30{ }^{\circ} \mathrm{C}$, aligned with our breakthrough curves of Starbons ${ }^{\circ}$. Tiwari et al. [31] also studied on Melamine-formaldehyde derived porous carbons in $\mathrm{CC}$ at a temperature of $30^{\circ} \mathrm{C}$ and for four different carbons (MFZ-500, MFZ-600, MFZ-700 and MFZ-800) on the breakthrough aspects of adsorption. The Table 4 below gives the breakthrough times of the referenced porous carbons vis-à-vis our Starbons .

\subsubsection{Carbon capture capacity}

Yu et al. [32] made a detailed review regarding the CC values of various solid porous adsorbents and amine impregnated sorbents the extracts of which were displayed in Tables 5 (unloaded) and 6 (amine loaded) below. From the results of the unloaded sorbents, it was clearly evident that though absolute CC values given by the Starbons ${ }^{\circledR}$ were relatively low, they were high if $C C$ per unit surface area was considered. In the other class of loaded sorbents, $30 \%$ MEA loaded Starbons ${ }^{\circledR}$ gave higher CC than almost
Table 4 Comparison of breakthrough times of Starbons ${ }^{\circledR}$ with other carbonaceous sorbents

\begin{tabular}{lll}
\hline Adsorbent & $\begin{array}{l}\text { Time taken for 100\% } \\
\text { saturation (min) }\end{array}$ & References \\
\hline PS-750 Starbon & 10 & In this study \\
10\% MEA loaded Starbon & 10 & In this study \\
20\% MEA loaded Starbon & 28 & In this study \\
$30 \%$ MEA loaded Starbon & 30 & In this study \\
C-500 & 17 & Ref [30] \\
C-600 & 17 & Ref [30] \\
C-700 & 23 & Ref [30] \\
C-800 & 15 & Ref [30] \\
MFZ-500 & 15 & Ref [31] \\
MFZ-600 & 10 & Ref [31] \\
MFZ-700 & 25 & Ref [31] \\
MFZ-800 & 5 & Ref [31] \\
\hline
\end{tabular}

Table 5 A comparison of CC values of other adsorbents with PS-750

\begin{tabular}{lll}
\hline Adsorbent used & $\begin{array}{l}\text { CC value } \\
\mathrm{mmol} / \mathrm{m}^{2} \text { of adsorbent }\end{array}$ & References \\
\hline MCM-41 & 0.0012 & {$[32]$} \\
SWCNT & 0.0025 & {$[32]$} \\
Graphene & 0.0051 & {$[32]$} \\
Meso-Carbon & 0.0018 & {$[32]$} \\
SBA-15 & 0.0006 & {$[32]$} \\
PS-750 & 0.006 & In this study \\
\hline
\end{tabular}

all other sorbents, which was even higher is CC per unit surface area was considered. Finally the ratio of porous surface area to pore volume is also an important factor to consider. Table 7 gives a comparison of the same. It can be observed that relative to its surface area, the PS Starbon has a high pore volume. This makes it potentially one of 
Table 6 A comparison of CC values of other amine impregnated adsorbents with $30 \%$ MEA PS 750

\begin{tabular}{llll}
\hline Adsorbent used & $\begin{array}{l}\text { Amine/base } \\
\text { employed } \\
\text { (\% by weight) }\end{array}$ & $\begin{array}{l}\text { CC value } \\
\text { mmol } / \mathrm{m}^{2}\end{array}$ & $\begin{array}{l}\text { References } \\
\text { of adsor- } \\
\text { bent }\end{array}$ \\
\hline MCM-41 & $50 \%$ PEI & 0.022 & {$[32]$} \\
Carbon Black & $50 \%$ PEI & 0.0021 & {$[32]$} \\
MCM-48 & $50 \%$ PEI & 0.0023 & {$[32]$} \\
SBA-15 & $35 \%$ TEPA & 0.0054 & {$[32]$} \\
AC & $31 \%$ PEHA & 0.0006 & {$[32]$} \\
MEA-PS 750 & $30 \%$ MEA & 0.001 & In this study \\
\hline
\end{tabular}

Table 7 A comparison of pore volumes and BET surface area values of other adsorbents with PS-750

\begin{tabular}{|c|c|c|c|}
\hline Adsorbent used & $\begin{array}{l}\text { BET surface area } \\
\left(\mathrm{m}^{2} / \mathrm{g}\right)\end{array}$ & $\begin{array}{l}\text { Pore volume } \\
\mathrm{cc} / \mathrm{g}\end{array}$ & References \\
\hline MCM-41 & 1267 & 0.32 & {$[32]$} \\
\hline SWCNT & 1587 & 1.55 & [32] \\
\hline Graphene & 1550 & - & {$[32]$} \\
\hline Meso-Carbon & 798 & 0.87 & {$[32]$} \\
\hline SBA-15 & 802 & 1.12 & {$[32]$} \\
\hline PS-750 & 230 & 0.298 & In this study \\
\hline
\end{tabular}

the best candidates for molecular capture studies. The study conducted in Lashaki et al. [33] explains the relation between pore volume and $\mathrm{CO}_{2}$ uptake. Loganathan et al. [34], in its CC experiments on MCM-41, also reported findings in agreement with Lashaki et al. [33]. In both the above studies, the trend was such that adsorbents with higher pore volumes exhibited higher CC values.

\section{Conclusions}

In this work, Starbons have been synthesized successfully from potato and corn starch using a standard protocol and both were found to exhibit similar physico-chemical properties. Potato starch based Starbons have been employed for all further studies due to shorter synthesis durations. It was found that amine loading by wet impregnation method could increase the surface area and hence CC. The effects of temperature, loading level and carbonation time on CC were studied and it was found that highest CC of nearly $3.4 \mathrm{mmol} / \mathrm{g}$ ads was shown at $500 \mathrm{C}$ and $30 \%$ loading with MEA. As far as cyclic stability was concerned, the loading percent was found to have a negative effect on CC achieved in subsequent cycles up to three cycles. Starbons ${ }^{\circ}$ were also compared with other loaded and unloaded sorbents reported in literature and it was found that Starbons gave reasonably good CC if it was considered per unit area. Amine loaded Starbons outperformed other loaded sorbents in absolute CC and even much better if unit surface area was considered. The pore volumes, another important factor determining the $\mathrm{CC}$ value is also relatively high for Starbons ${ }^{\circ}$ in comparison to other similar activated carbons. Hence this reveals that Starbons have great potential as green, economical and effective sorbents in CC. Future studies should focus on more innovative synthesis protocols and novel dopants and protocols to increase surface area and hence CC and cyclic stability.

\section{Compliance with ethical standards}

Conflict of interest I, on behalf of the authors wish to declare that there are no conflicts of interest of any type in this work.

\section{References}

1. Bahadori A, Vuthaluru HB (2009) New method accurately predicts carbon dioxide equilibrium adsorption isotherms. Int $J$ Greenh Gas Control 3(6):768-772

2. Sreenivasulu B, Gayatri DV, Sreedhar I, Raghavan KV (2015) A journey into the process and engineering aspects of carbon capture technologies. Renew Sustain Energy Rev 41:1324-1350

3. Sreenivasulu B, Suresh P, Sreedhar I, Raghavan KV (2015) Development trends in porous adsorbents for carbon capture. Environ Sci Technol 49(21):12641-12661

4. Wang J, Huang L, Yang R, Zhang Z, Wu J, Gao Y, Wang Q, O'Hareb D, Zhong Z (2014) Recent advances in solid sorbents for $\mathrm{CO}_{2}$ capture and new development trends. Energy Environ Sci 7:3478

5. Lee S-Y, Park S-J (2015) A review on solid adsorbents for carbon dioxide capture. J Ind Chem Eng 23:1-11

6. Sevilla M, Fuertes $A B$ (2011) Sustainable porous carbons with a superior performance for $\mathrm{CO}_{2}$ capture. Energy Environ Sci 4(5):1765-1771

7. Ruiz B, Ferrera-Lorenzo N, Fuente E (2017) Valorisation of lignocellulosic wastes from the candied chestnut industry. Sustainable activated carbons for environmental applications. J Environ Chem Eng 5(2):1504-1515

8. Parshetti GK, Chowdhury S, Balasubramanian R (2015) Biomass derived low-cost microporous adsorbents for efficient $\mathrm{CO}_{2}$ capture. Fuel 148:246-254

9. Mohamed AR, Mohammadi M, Darzi GN (2010) Preparation of carbon molecular sieve from lignocellulosic biomass: a review. Renew Sustain Energy Rev 14(6):1591-1599

10. Boujibara O, Souiknya A, Ghamouss F, Achaka O, Dahbi M, Chafika $\mathrm{T}$ (2018) $\mathrm{CO}_{2}$ capture using $\mathrm{N}$-containing nanoporous activated carbon obtained from Argan. J Environ Chem Eng 6(2):1995-2002

11. Shen F, Wang Y, Li L, Zhang K, Smith RL Jr, Qi X (2017) Porous carbonaceous materials from hydrothermal carbonization and $\mathrm{KOH}$ activation of corn stover for highly efficient carbon capture. Chem Eng Commun 205:423-431. https://doi. org/10.1080/00986445.2017.1367671

12. Budarin V, Clark JH, Luque R, White R (2009) Starbons : cooking up nanostructured mesoporous materials. Mater Matters 4(1):19 
13. Shuttleworth $P$, Budarin V, Breeden SW, Macquarrie $D$, Luque R, White R, Clark JH (2011) Starbon": preparation, applications and transition from laboratory curiosity to scalable product. In: Technical proceedings of the 2011 NSTI nanotechnology conference and expo, NSTI-Nanotech 2011, vol 3, pp 766-769

14. Sanz-Pérez ES, Arencibia A, Sanz R et al (2016) New developments on carbon dioxide capture using amine-impregnated silicas. Adsorption 22:609

15. Sreenivasulu B, Sreedhar I, Reddy BM, Raghavan KV (2017) Stability and carbon capture enhancement by coal-fly-ash-loaded sorbents at a high temperature. Energy Fuels 31:785-794

16. Abulencia JP, O'Brien S, Gallardo S, Tanala FN (2012) A sustainable water purification solution for rural communities. Int J Environ Pollut Remediat 1:75-81

17. Isik-Gulsac I (2016) Investigation of impregnated activated carbon properties used in hydrogen sulfide fine removal. Braz J Chem Eng 33:1021-1030

18. Shang H, Lu Y, Zhao F, Chao C, Zhang B, Zhang H (2015) Preparing high surface area porous carbon from biomass by carbonization in molten salt medium. RSC Adv 5:75728-75734

19. Liu D, Zeng C, Tang H, Zheng D, Li R, Qu D, Xie Z, Lei J, Xiao L, Qu $D$ (2014) Electrochemical hydrogen storage in a highly ordered mesoporous carbon. Front Energy Res 2:42

20. Shu Y, Li K, Song J, Li B, Tang C (2016) Single and competitive adsorption of $\mathrm{Cd}(\mathrm{II})$ and $\mathrm{Pb}$ (II) from aqueous solution by activated carbon prepared with Salix matsudana Kiodz activated carbon. Water Sci Technol 74(12):2751-2761

21. Cogswell CF, NigITP, Stavola A, Wolek A, Wang Y, Zummo J, Lin Y, Dukaye L, Chinn R, Choi S (2019) Generation and use of a pure titanium pillared MCM-36 structure as a high efficiency carbon dioxide capture platform and amine loaded solid adsorbent. Microporous Mesoporous Mater 280:151-156

22. Liu F, Chen S, Gao Y, Xie Y (2017) $\mathrm{CO}_{2}$ adsorption behavior and kinetics on polyethylenimine modified porous phenolic resin. $J$ Porous Mater 20:1-8

23. Son W-J, Choi J-S, Ahn W-S (2008) Adsorptive removal of carbon dioxide using polyethyleneimine-loaded mesoporous silica materials. Microporous Mesoporous Mater 113(1-3):31-40

24. Li Y, Ruan G, Jalilov AS, Tarkunde YR, Fei H, Tour JM (2016) Biochar as a renewable source for high-performance $\mathrm{CO}_{2}$ sorbent. Carbon 107:344-351
25. Gholidoust A, Atkinson JD, Hashisho Z (2017) Enhancing $\mathrm{CO}_{2}$ adsorption via amine impregnate activated carbon from oil sands coke. Energy Fuels 31(2):1756-1763

26. Fiuza RA Jr, Andradea RC, Andrade $\mathrm{HN}(2016) \mathrm{CO}_{2}$ capture on $\mathrm{KOH}$-activated carbons derived from yellow mombin fruit stones. J Environ Chem Eng 4(4):4229-4236

27. Li Y, Wen X, Li L, Wang F, Zhao N, Xiao F, Wei W, Sun Y (2013) Synthesis of amine-modified mesoporous materials for $\mathrm{CO}_{2}$ capture by a one-pot template-free method. J Sol-Gel Sci Technol 66(3):353-362

28. Ma L, Bai R, Hu G, Chen R, Hu X, Dai W, DaCosta HFM, Fan M (2013) Capturing CO2 with amine-impregnated titanium oxides. Energy Fuels 27(9):5433-5439

29. Nguyen M-V, Lee B-K (2016) A novel removal of $\mathrm{CO}_{2}$ using nitrogen loaded Biochar beads as a green adsorbent. Process Saf Environ Prot 104(1):490-498

30. Goel C, Bhunia H, Bajpai PK (2016) Novel nitrogen enriched porous carbon adsorbents for $\mathrm{CO}_{2}$ capture: breakthrough adsorption study. J Environ Chem Eng 4(1):346-356

31. Tiwari D, Goel C, Bhunia H, Bajpai PK (2017) Melamine-formaldehyde derived porous carbons for adsorption of $\mathrm{CO}_{2}$ capture. J Environ Manag 197:415-427

32. Yu C-H, Huang C-H, Tan C-S (2012) A review of $\mathrm{CO}_{2}$ capture by absorption and adsorption. Aerosol Air Qual Res 12:745-769

33. Lashaki MJ, Sayari A (2018) $\mathrm{CO}_{2}$ capture using triamine-grafted SBA-15: the impact of the support pore structure'. Chem Eng J 334:1260-1269

34. Loganathan S, Ghoshal AK (2017) Amine tethered poreexpanded MCM-41: a promising adsorbent for $\mathrm{CO}_{2}$ capture. Chem Eng J 308:827-839

Publisher's Note Springer Nature remains neutral with regard to jurisdictional claims in published maps and institutional affiliations. 